\title{
ENTREPRENEURSHIP: STRATEGI PEMASARAN DAN PENGEMBANGAN PRODUK USAHA RUMAH BATIK SETU DI TANGERANG SELATAN
}

\author{
Rodhiah $^{1}$, M TonyNawawi ${ }^{2}$, dan Toto Mujio Mukmin ${ }^{3}$ \\ ${ }^{1}$ Jurusan Manajemen Fakultas Ekonomi dan Bismis, Universitas Tarumanagara Jakarta \\ Email: rodhiah@fe.untar.ac.id \\ ${ }^{2}$ Jurusan Manajemen Fakultas Ekonomi dan Bismis , Universitas Tarumanagara Jakarta \\ Email: tonyn@fe.untar.ac.id \\ ${ }^{3}$ program Studi DKV Fakultas FSRD , Universitas Tarumanagara Jakarta \\ Email: totom@fsrd.untar.ac.id
}

\begin{abstract}
PKM activities are a continuation of previous activities. Where this advanced entrepreneurship program is focused on training activities on marketing and product development. The partner in the activity is the Setu batik home business cooperative group in South Tangerang. Given that there are still partners' problems regarding marketing strategies and product development that have not been carried out optimally. For this reason, PKM activities aim to provide understanding to partners about marketing strategies and product development strategies, so that partners can have knowledge in increasing batik sales. The method used includes: training in marketing theory and product development. Provide assistance in preparing product development steps. The results of the activity indicated that there was an increase in partners' knowledge about marketing and product development. The training provided on marketing strategies, namely product strategy, price, place and promotion has run smoothly. Training and socialization on product development, and entrepreneurship programs have been conducted in accordance with the needs of partners. Includes an explanation of the stages of product development consisting of: Idea generation; Idea screening;. Development and Testing concept;Marketing strategy development;Business analysis; Product development;Market testing and Commercialization. This training has provided partner insights for new product development with simple motives. Furthermore, partners can develop products in an effort to increase the variety of products to be sold.
\end{abstract}

Keywords: marketing, product development, training, mentoring

\begin{abstract}
ABSTRAK
Kegiatan PKM merupakan kelanjutan dari kegiatan sebelumnya. Program enterpreneurship lanjutan ini difokuskan pada kegiatan pelatihan tentang pemasaran dan pengembangan produk. Mitra yang menjadi tempat kegiatan adalah kelompok koperasi usaha rumah batik Setu di Tangerang Selatan. Mengingat masih adanya permasalahan mitra tentang strategi pemasaran dan pengembangan produk belum dilakukan secara optimal. Untuk itu kegiatan PKM bertujuan memberikan pemahaman pada mitra tentang strategi pemasaran dan strategi pengembangan produk, agar mitra dapat memiliki bekal pengetahuan dalam meningkatkan penjualan batik. Metode yang dilakukan meliputi:pelatihan teori pemasaran,dan pengembangan produk. Melakukan pendampingan dalam menyusun langkah langkah pengembangan produk. Hasil kegiatan menunjukkan terjadi peningkatan pengetahuan mitra tentang pemasaran Pelatihan yang diberikan tentang strategi pemasaran yaitu strategi produk, price,place dan promotion telah berjalan dengan lancar. Pelatihan dan sosialisasi tentang pengembangan produk, dan program entrepreneurship telah dilakukan sesuai dengan kebutuhan mitra. Meliputi penjelasan tahapan pengembangan produk terdiri dari: Idea generation (Pemunculan gagasan). Idea screening (Penyaringan gagasan). Concept development and testing (Pengembangan dan Pengujian konsep.) Marketing strategy development (Pengembangan strategi pemasaran). Business analysis (Analisis bisnis). Product development (Pengembangan produk), Market testing (Pengujian pasar) dan Commercialization (Komersialisasi). Pelatihan ini telah memberikan wawasan mitra untuk pengembangan produk baru dengan motif yang sederhana. Selajutnya mitra dapat melakukan pengembangan produk dalam upaya meningkatkan variasi produk yang akan dijual.
\end{abstract}

Kata kunci: pemasaran, pengembangan produk,pelatihan, pendampingan

\section{PENDAHULUAN}

Dewasa ini persaingan bisnis yang semakin tajam. Produk-produk yang diciptakan satu sama lain bersaing dalam merebut pasar. Berbagai pilihan produk yang beragam menjadi alternatif pilihan konsumen sebelum memutuskan sebagai pengguna akhir. Salah satu hal yang perlu diperhatikan 
dalam menarik dan merebut konsumen adalah pemasaran. Pemasaran merupakan bagian yang sangat penting bagi seorang pengusaha, oleh karena itu pengusaha harus memahami dan memiliki strategi pemasaran, dalam memasarkan produk secara lebih baik dari pesaing. Tapia, et al., (2010)"menemukakan salah satu bentuk dari strategi bisnis adalah strategi pemasaran" (Sara. 2010) menjelaskan" banyak kasus UKM di Indonesia yang tidak dapat melakukan strategi pemasaran yang tepat", kecenderungnya UKM di Indonesia hanya "menunggu konsumen" dan monoton dalam melakukan kegiatan pemasaran". Konsep manajemen pemasaran menyebutkan bahwa tujuan utama pemasaran adalah mencapai target dan pangsa pasar yang luas. Cravens dan Piercy (2006) menjelaskan konsep manajemen pemasaran memiliki tujuan utama untuk mencapai target dan sasaran pemasaran. Melalui unggkapan tersebut maka pengusaha dan UKM perlu mempertahankan target pelanggan yang sudah ada dan memperluas pelanggan baru.

Menyimak kondisi konsumen yang memiliki selera dan permintaan yang selalu berubah-ubah dan tidak puas, menyebabkan perusahaan harus dapat kreatif dan lebih kritis dalam menghadapi keinginan pasar. Melalui pengembangan produk yang dimodifikasi menjadi produk yang lebih kreatif dan inovatif akan dapat memuaskan keinginan konsumen. Kotler (2015) menjelaskan "Pengembangan dari produk orisinil,peningkatan produk, modifikasi produk, dan merek produk melalui usaha pengembangan perusahaan, agar dapat menghasilkan suatu produk yang menguasai pasar dan memenuhi kebutuhan konsumen". Pengembangan produk atau menciptakan produk baru merupakan tugas yang sering terlupakan. Oleh karena itu perusahaan perlu menerapkan strategi entrepneurship." Entrepreneurship dipengaruhi oleh target dan pengalaman entrepreneur dalam menjalankan bisnis "Jabeen, F., Faisal, M. N., \& I. Katsioloudes, M. (2017), Orser (2011). Sementara itu Sakalieh (2010) :mengamati bahwa entrepreneurship yang berdasarkan pada keterampilan-keterampilan tertentu menjadi ciri khas para entrepreneur dalam melakukan pengembangan suatu produk". Untuk mewujudkan hal tersebut, sumber pengetahuan menjadi bekal dalam proses pengembangan suatu produk. Robert D. Hisrich (2005) berpendapat pengetahuan memiliki peranan penting untuk menunjang sebuah usaha dan bisnis agar tepat sasaran. Melalui program enterpreneurship akan memberikan daya tarik pada pengembangan pengetahuan, juga menjadi bekal pengembangan produk usaha yang baru.

Mitra yang akan dibina dalam kegiatan ini meliputi kelompok masyarakat yang bernaung pada kelompok koperasi usaha Rumah Batik Setu , dengan pengurus 8 orang, ketua bernama Ibu Mayunih. Anggota koperasi 40 ,. Dengan nomor akte pendirian no 46, tgl 21 November 2017 dengan notaris Rani Ridayanthi, Sarjana Hukum, Magister Hukum. Berdasarkan surat keputusan mentri Negara Koperasi dan Usaha Kecil dan Menengah Republik Indonesia, nomor: 0001/Kep/M.KUKM/X/2004, tanggal 12 Oktober 2004. Kelompok ini memiliki potensi untuk dikembangkan. Melalui gambaran strategi pemasaran yang sudah dilakukan maupun pengembangan produk, masih belum dilakukan secara optimal. Kondisi tersebut terkait dengan pengetahuan mitra akan strategi pemasaran yang meliputi strategi produk, price, place dan promosi masih rendah. Selain itu, pemahaman mitra tentang strategi pengembangan produk juga masih kurang. Untuk itu TIM PKM Untar merasa penting untuk mentransfer IPTEKs yang dimiliki masing-masing bidang dari anggota tim, dalam mengatasi persoalan mitra. Kegiatan ini bertujuan untuk meningkatkan pengetahuan di bidang pemasaran dan pengembangan produk.

\section{METODE PELAKSANAAN}

Berdasarkan permasalahan yang dihadapi kelompok koperasi batik Setu, maka solusi yang ditawarkan berupa: 


\section{Pelatihan/ Sosialisasi}

Kegiatan sosialisasi dilakukan untuk memberikan pembekalan terhadap pemahaman tentang pengetahuan strategi pemasaran, dan pengembangan produk. Untuk melaksanakan kegiatan sosialisasi ini, ada beberapa langkah yang perlu dilakukan.

a. Tim PKM sebagai tutor menghubungi pihak terkait, yaitu ketua koperasi yaitu ibu Mayunih untuk minta ijin melakukan sosialisasi.

b. Tim PKM sebagi tutor berkoordinasi dengan ketua bidang usaha yaitu ibu Diana agar dapat memberikan jadwal untuk melakukan kegiatan sosialisasi.

c. Tim PKM sebagai tutor menyampaikan materi sosialisasi melalui ceramah, diskusi, dan tanya jawab. sosialisasi tentang pemasaran dan strategi pengembangan produk

d. Tutor mejelaskan tentang apa yang harus dilakukan ketua dan anggota koperasi rumah batik Setu dalam menjalankan program pemasaran dan pengembangan produk batik secara lebih terencana dan teratur.

e. Mitra mendengarkan dan memberikan respon pada tim PKM atas materi sosialisasi

\section{Pendampingan}

Kegiatan pendampingan dilakukan dalam menyusun rencana strategi pengembangan produk. Adapun Langkah Langkah yang dikaukan:

a. Tim membuat dan mengecek produk yang sudah diproduksi sebelumnya

b. Tim melakukan penjajakan

c. Tim mendatangi mempelajari beberpa alternatif strategi rencana pengembangan produk

d. Tim melakukan FGD untuk pilihan pengembangan produk

e. Tim beserta mitra melakukan proses seleksi beberapa alternative pilihan strategi pengembangan produk

f. Tim menyampaikan evaluasi dari beberapa alternative strategi

g. Tim memberikan masukan rencana pengembangan produk yang sebaiknya akan dilakukan

\section{HASIL DAN PEMBAHASAN}

\section{Gambaran Rumah Batik Setu}

Bermula dari pelatihan membatik yang diadakan oleh kecamatan setu pada tanggal Oktober 2017, sebagai kelanjutannya maka dibentuknya koperasi dengan nama rumah batik setu sebagai upaya untuk melestarikan batik dan memberdayakan masyarakat guna perbaikan ekonomi , khususnya masyarakat wilayah setu. Rumah Batik Setu dibawah naungan koperasi usaha, dengan pengurus 8 orang, ketua bernama Ibu Mayunih. Anggota koperasi 40 . Dengan nomor akte pendirian no 46, tgl 21 November 2017 dengan notaris Rani Ridayanthi, Sarjana Hukum, Magister Hukum. Berdasarkan surat keputusan mentri Negara Koperasi dan Usaha Kecil dan Menengah Republik Indonesia, nomor: 0001/Kep/M.KUKM/X/2004, tanggal 12 Oktober 2004. Walaupun baru berdiri 3 tahun, kelompok ini memiliki potensi untuk dikembangkan.Potensi local adanya: ketersediaan masyarakat yang produktif, kersediaan lahan tempat untuk produksi, ketersediaan sumberdaya alam untuk pewarnaan batik, ketersediaan air yang. Kondisi alam yang masih mendukung, belum ada pesaing, sangat diperlukan dalam pengembangan potensi masyarakat usaha Batik. Potensi tersebut menjadi peluang bagi kelompok ini untuk berkembang. Rumah batik beralamat di Kecamatan Setu masih memiliki teknik membatik tradisional dilakukan dengan tangan,menggunakan canting tulis dan pewarnaan, tahan-lilin pada tekstil dalam proses pembuatannya. Sehingga ciri khas tradisional masih sangat kental motif batik yang dimiliki oleh rumah batik setu. Gambaran sekitar tempat kegiatan membatik mitra adalah: 


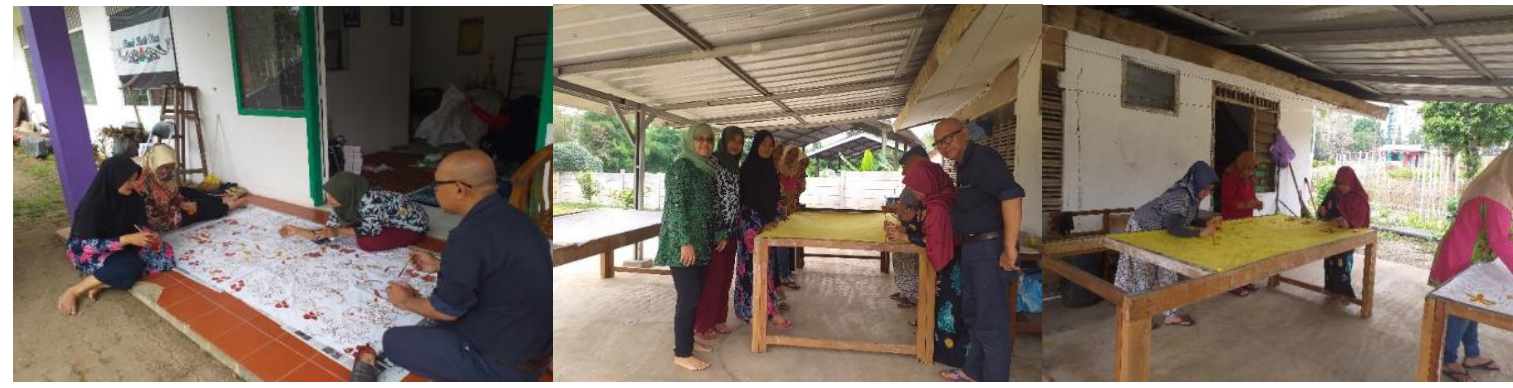

Gambar 1. Kondisi Sekitar rumah Batik

\section{Pemahaman tentang Strategi Pemasaran}

Untuk melakukan kegiatan usaha mitra, maka diperlukan strategi pemasaran yang tepat. Spesifikasi model yang diberikan pada mitra UKM Batik berupa "pemberian pengetahuan tentang strategi pemasaran, melalui kegiatan pelatihan atau sosialisasi yang terkait dengan strategi pemasaran dalam pengembangan usaha.

Model yang ditawarkan dalam strategi pemasaran mengadopsi dari hasil dari beberapa teori dan jurnal. Kegiatan pemasaran dalam unsur bauran adalah aktivitas yang dilakukan oleh perusahaan untuk memasarkan sebuah produk dimana variabel kegiatan marketing mix (bauran pemasaran) terdiri dari empat pokok utama: produk, tempat, promosi, harga. Berikut adalah penjelasan dari masing-masing unsur tersebut:

Product (Produk), Kotler (2015) “ mengatakan produk adalah segala sesuatu yang dapat ditawarkan ke dalam pasar untuk diperhatikan, dimiliki, digunakan dan dikonsumsi sehingga dapat memuaskan keinginan dan kebutuhan. Termasuk di dalamnya adalah objek fisik, jasa, orang, tempat, organisasi dan gagasan" .Produk adalah "suatu yang dapat ditawarkan kepasar untuk mendapatkan perhatian, untuk dibeli, digunakan/dikonsumsi yang dapat memenuhi suatu keinginan/kebutuhan" (Umar, 2005), Aktivitas produk dapat meliputi kualitas , keragaman, kemasan, motif, warna maupun garansi.

Price (Harga), Harga merupakan alat bauran pemasaran yang penting karena menggambarkan balas jasa yang tegas dan jelas terhadap produk yang diperoleh. Kotler (2015) "menjelaskan harga adalah sejumlah uang atau produk yang dibutuhkan untuk memperoleh produk lain".

Place (Saluran Distribusi), Kotler (2015) menjelaskan “ distribusi sebuah produk akan intensif ketika produk itu ditempatkan dibanyak toko untuk memenuhi kebutuhan pasar". "Untuk mengangkat citra produk dan memperoleh bantuan dari ritel, perusahaan cenderung mendistribusikan produknya secara ekslusif dan selektif dibandingkan secara intensif" (Yoo et al, 2000).

Promotion (Promosi),Kotler (2015) menjelaskan"Promosi merupakan suatu alat yang di pakai untuk menginformasikan, mempengaruhi dan mengingatkan kepada konsumen akan produk yang ditawarkan perusahaan".Tjiptono (2004), promosi adalah "suatu bentuk komunikasi pemasaran, merupakan aktivitas pemasaran yang berusaha menyebarkan informasi, mempengaruhi atau membujuk, dan mengingatkan pasar sasaran atas perusahaan dan produknya agar bersedia menerima, membeli dan loyal pada produk yang ditawarkan perusahaan yang bersangkutan”.

\section{Pemahaman tentang pengembangan produk}

Pengembangan produk merupakan suatu usaha adalah untuk meningkatkan alokasi sumber daya, meningkatkan arus informasi, mengurangi waktu dan biaya pengembangan, meminimalkan risiko 
dan kegagalan, dan mencapai kesuksesan setelah produk dikembangkan. Perusahaan harus mampu secara aktif menciptakan dan memenuhi kebutuhan konsumen sekaligus meningkatkan keuntungan perusahaan. Menurut Cooper (2008) untuk menciptakan pengembangan produk baru maka terdapat hal yang perlu diperhatiakn perusahaan yaitu: Produk harus dibedakan di pasar, sediakan manfaat bagi pengguna, dan menargetkan pasar yang menarik. Dalam pelaksanaan sosialisasi secara langsung ke tempat mitra telah didokumentasikan pada gambar 2.

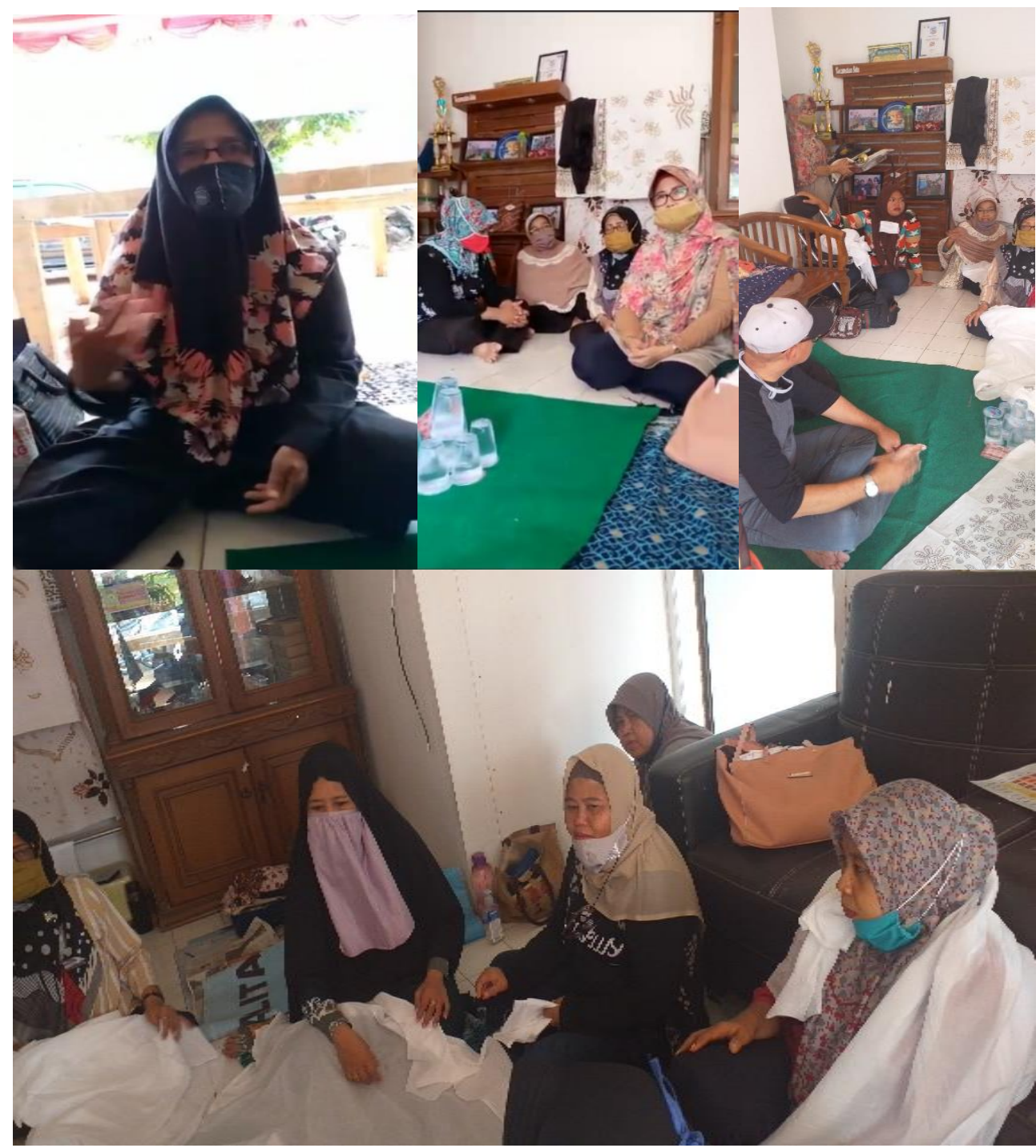

Gambar 2. Kegiatan Sosialisasi

\section{Pendampingan menyusun strategi pengembangan produk}

Output yang diingkan dari kegiatan ini, terbentunya rancangan bagi mitra untuk dapat mengembangkan produk yang sesuai dengan keadaan pasar. Untuk itu hasil dari kegiatan pendampingan berupa:

a. Mitra dapat mengembangkan ciri-ciri produk dengan menyesuaikan, mengubah, memperbesar, memperkecil, mengganti atau menyusun kembali penampilan yang sudah ada. Pengembangan produk dilaksanakan akibat timbulnya perubahan permintaan konsumen yang ada hubungannya dengan bentuk produk sehingga perlu mendesain kembali produk yang telah ada di pasar.

b. Mitra dapat membeli produk dengan kualitas berbeda

c. Mitra dapat mengembangkan model tambahan dan ukuran yang berbeda. 
Agar mitra dapat menghasilkan produk yang benar-benar diinginkan konsumen, dalam melaksanakan kebijakan pengembangan produk mitra harus memperhatikan tahap-tahap melaksanakan pengembangan produk.

1). Idea generation (Pemunculan gagasan). Proses pengembangan produk baru berawal dari pencarian gagasan. Ketua koperasi dan pengurus harus berani membuat terobosan, memodifikasi produk lama dan meniru produk pesaing. Gagasan produk baru dapat berasal dari banyak sumber: pelanggan, ilmuwan, pegawai, pesaing, saluran pemasaran dan manajemen puncak. Tim memberikan penilaian terhadap produk yanga sudah ada, selanjunya 2). Idea screening (Penyaringan gagasan). Proses pengembangan produk baru berawal dari pencarian gagasan. Ketua koperasi dan pengurus harus berani membuat terobosan, memodifikasi produk lama dan meniru produk pesaing. Gagasan produk baru dapat berasal dari banyak sumber: pelanggan, ilmuwan, pegawai, pesaing, saluran pemasaran dan manajemen puncak. Tim memberikan penilaian terhadap produk yanga sudah ada, selanjunya 3). Concept development and testing (Pengembangan dan Pengujian konsep.) Gagasan yang menarik harus disempurnakan menjadi konsep produk yang dapat diuji. Hal ini dapat dibedakan menjadi gagasan produk, konsep produk dan citra produk

4). Marketing strategy development (Pengembangan strategi pemasaran). Mitra harus mengembangkan rencana awal strategi pemasaran untuk memperkenalkan produk baru itu ke pasar. Strategi pemasaran akan mengalami penyempurnaan lebih lanjut dalam tahap-tahap berikutnya

5). Business analysis (Analisis bisnis). Dilakukan setelah mitra mengembangkan konsep produk dan strategi pemasaran, yaitu dengan mengevaluasi daya tarik bisnis dari proposal itu. Mitra perlu mempersiapkan proyeksi penjualan, biaya dan laba untuk menentukan apakah semua itu memenuhi tujuan usaha. Jika memenuhi, konsep produk tersebut dapat dilanjutkan ke tahap pengembangan produk.

6). Product development (Pengembangan produk), mitra perlu melakukan satu atau beberapa dari pengembangan konsep yang sudah disepakati sebelumnya.

7) Market testing (Pengujian pasar) Mmitra menguji produk baru dalam lingkungan konsumen yang nyata dan mempelajari seberapa besar pasar itu dan bagaimana konsumen dan penyalur bereaksi untuk menangani, menggunakan dan membeli kembali produk actual. Pengujian pasar dipengaruhi biaya dan resiko investasi di satu sisi dan tekanan waktu serta biaya riset di sisi lain.

8). Commercialization (Komersialisasi). Mitra dapat meluncurkan produk baru dengan tempat, wilayah pemasaran strategi pasar dan pasar sasaran yang ditentukan.

Melalui pembekalan dan pendampingan tersebut, telah menghasilkan bentuk pengembangan produk baru mutra yang telah berhasil dibuat bersama tim PKM. Dokumentasi dalam bentuk foto dapat dilihat pada Gambar 3.

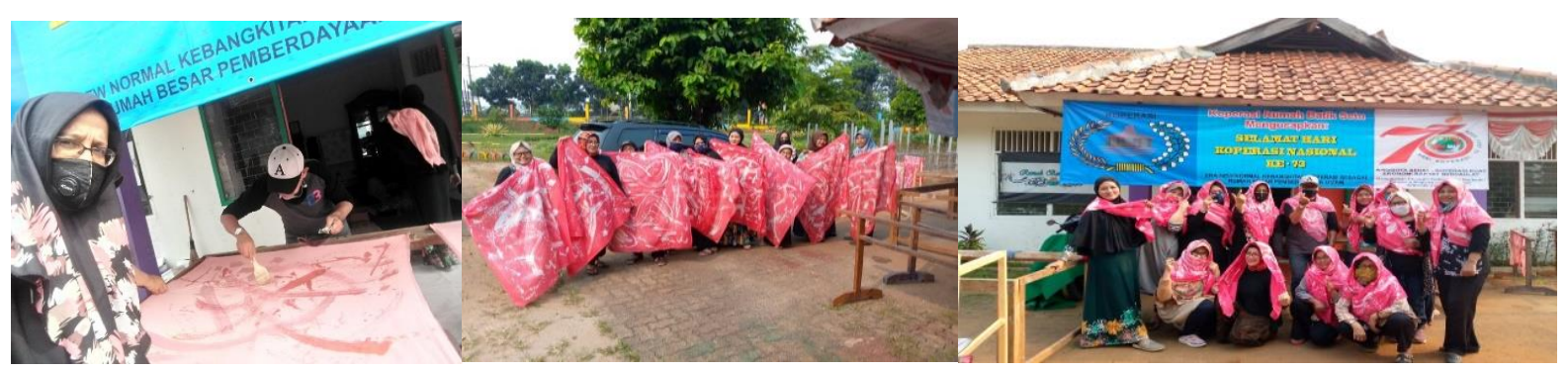

Gambar 3. Kegiatan Pendampingan Pengembangan Produk 


\section{KESIMPULAN DAN SARAN}

Berdasarkan pelaksanaan kegiatan ini, diperoleh simpulan sebagai berikut:

a. Pelatihan tentang strategi pemasaran diberikan dengan cara mensosialisasikan kepada mitra tentang strategi produk, price,place dan promotion berjalan dengan lancar.

b. Pelatihan dan sosialisasi tentang pengembangan produk, dan program entrepreneurship telah dilakukan sesuai dengan kebutuhan mitra. Meliputi penjelasan singkat perlunya pengembangan produk baru dengan motif yang sederhana.

c. Praktek pendampingan pengembangan produk telah dilakukan sesuai dengan kebutuhan mitra.

d. Mitra bersemangat menerima materi dan praktek pengembangan produk yang sudah dipraktekkan, dengan menghasilkan variasi motif yang beragam.

Perbaikan secara berkelanjutan pada koperasi usaha rumah batik Setu terus dapat dilakukan, antara lain dapat dikembangkan dalam kajian selanjutnya.

a. Proses pembinaan kontinuitas usaha, melalui evaluasi dari proses dan pendampingan yang sudah dibuat.

b. Kegiatan lanjutan akan dilakukan seperti kegiatan pelatihan dan pendampingan mengenai desain motif pada kaos kaos. .

c. Melakukan kerja sama dengan warga setempat untuk memberikan peluang bagi warga yang ingin belajar membatik. Sehingga rumah batik setu dapat menjadi kampung batik Setu.

\section{Ucapan Terima Kasih (Acknowledgement)}

Terima kasih kepada LPPM Untar yang telah memberikan pendanaan pada kegiatan PKM sehingga dapat diselesaikan tepat pada waktunya. Terima kasih juga kepada mitra yaitu pengurus dan anggota koperasi usaha batik setu yang telah mengikuti kegiatan PKM sampai selesai.

\section{REFERENSI}

Cooper, R. G (2008). Perspective: the stage-gates idea-to-launch process-update, what's new, and NexGen Systems. Journal of Product Innovation Management,v.25,n.3.p.213-232,. http://dx.doi.org/10.1111/j.1540- 5885.2008.00296.x..

Hisrich, Robert D. Peter Michael P and Stepherd Dean A, (2005). Entrepreneurship, Sixth Edition. New York: McGrawhill

Jabeen, F., Faisal, M. N., \& I. Katsioloudes, M. (2017). Entrepreneurial mindsetand the role of universities as strategic drivers of entrepreneurship: Evidence from the United Arab Emirates. Journal of Small Business and Enterprise Development, 24(1), 136-157.

Kobia, M. and Sakalieh, D. (2010). "Towards a search for the meaning of entrepreneurship". Journal of European Industrial Training, Vol. 34 No. 2, pp 110-127Kuratko, D. and Hodgett

Kotler P. and Kevin Lane Keller (2015). Marketing Management, 14th Edition. New Jersey: Prentice Hall Published

Orser, B.J., Elliott, \& C., Leck. (2011). Feminist attributes and entrepreneurial identity. Gender in Management: An International Journal,Vol. 26 No. 28, pp 561-589

Tapia, Martin Innaculada et all. (2010). Environmental strategy and exports in medium, small. And micro-enterprises. Journal of world business 45 (2010) 266-275. 
Umar H. (2008). Strategic Managementin Action. Cetakan Kelima .Jakarta: PT Gramedia Pustaka Utama

Yoo, Boonghee, Donthu, Naveen dan Lee, Sungho (2000), “An examination of selected marketing mix elements and brand equity”, Academy of Marketing Science Journal, Vol. 28 No. 2, p. 195-211. 